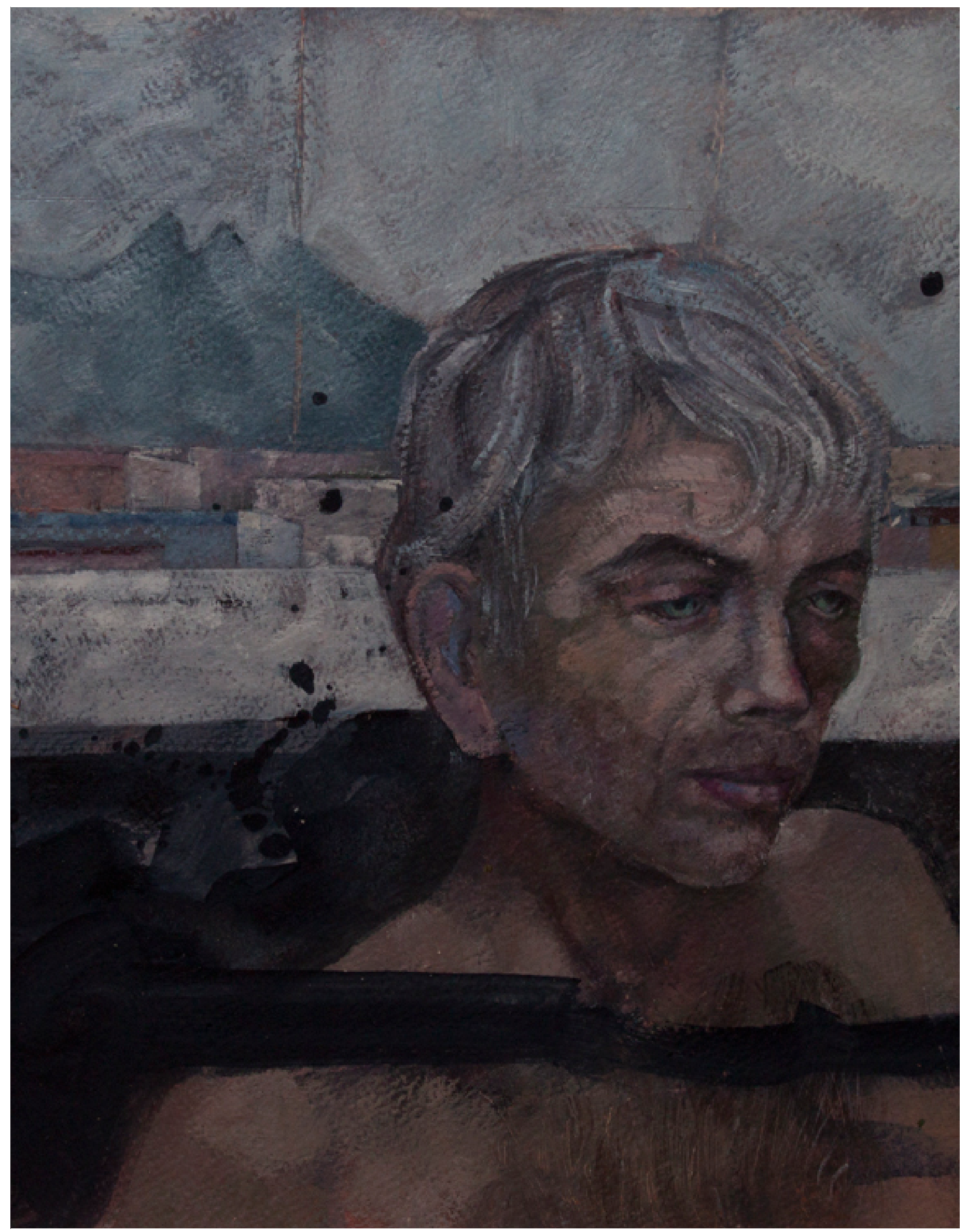

HOMBRE EN LA VENTANA (2012) | Temple sobre papel | $0.29 \times 0.34 \mathrm{mts}$ 


\section{EFICAGIA DE UN PROGRAMA FORMATIVO EN LÍNEA}

\section{EFFECTIVENESS OF AN ONLINE TRAINING PROGRAM}

RESUMEN

El progreso social se encamina proporcionalmente a la calidad del sistema educativo que mantenga cada nación, a sabiendas que éste es uno de los elementos más poderosos para contrabalancear las condiciones desfavorables presentes en el entorno. $Y$ dado que cada sistema educativo es tan bueno como el profesorado que lo conforma, de ellos depende en gran medida no sólo la consecución de una experiencia escolar óptima, sino en general, el éxito de las reformas y procesos educativos; siendo que una didáctica deficiente es más propensa a suscitar una marginación social. La presente investigación de corte cuantitativo descriptivo tiene por objeto analizar la eficacia generada al diseñar e implementar un e-course de gestión educativa como herramienta complementaria de formación para el desarrollo de profesionales de la educación. La selección de los sujetos de estudio se llevó a cabo a través de un muestreo no probabilístico voluntario, en el que se contó con la participación de 211 individuos provenientes de 20 instituciones de educación superior, pertenecientes a 14 países miembros de la Red de Apoyo a la Gestión Educativa, una asociación científica sin ánimo de lucro, orientada a promover, fortalecer y mejorar la gestión educativa en Iberoamérica. Como técnica de recolección de datos se recurrió a la encuesta mediante el uso de cuestionarios como instrumento y fuente primaria de información cuantitativa y cualitativa; mientras que para la fase de análisis se hace uso del software estadístico Minitab 19.
ABSTRACT

Social progress is directed proportionally to the quality of the educational system that each nation maintains, knowing that this is one of the most powerful elements to counterbalance the unfavorable conditions present in the environment. Each educational system is only as good as the teachers that make it up, not only the achievement of an optimal school experience depends on them to a great extent, but in general, the success of educational reforms and processes; being that a deficient didactics is more prone to arouse social marginalization. The present descriptive quantitative research aims to analyze the efficiency generated when designing and implementing an educational management e-course as a complementary training tool for the development of education professionals. The selection of study subjects was carried out through a voluntary non-probabilistic sampling, in which 211 individuals from 20 higher education institutions, belonging to 14 member countries of the Support Network, participated. to Educational Management, a non-profit scientific association, aimed at promoting, strengthening and improving educational management in Latin America. As a data collection technique, the survey was used through the use of questionnaires as an instrument and primary source of quantitative and qualitative information; while for the analysis phase, the statistical software Minitab 19 is used. 
egún explica el Instituto de Estadística de la Organización de las Naciones Unidas para la Educación, la Ciencia y la Cultura (UNESCO), el contexto educativo encara una escasez mundial de educadores debidamente formados; expresando que para el año 2030 se espera una demanda de 68,830 millones de profesionales de la enseñanza a nivel primaria y secundaria, siendo 5,429 millones destinados a Latinoamérica (de los cuales 5.068 estarían a cargo de sustituir a los docentes próximos a partir y los 0.361 restantes, representarían el número de profesores adicionales necesarios para abastecer el incremento en la cantidad de alumnado) (UIS, 2016).

Sin embargo, la situación en la región no está marcada por un déficit en la disponibilidad de profesores, sino en sus debilidades de formación en términos de suficiencia y relevancia; ya que en el periodo 2017-2018, a nivel mundial sólo el $86.6 \%$ del personal docente a nivel primaria y secundaria fue capacitado, cifra cercana al $86.3 \%$ que logra vislumbrarse en Latinoamérica (UIS, 2019). Y en adición a ello, según explica la UNESCO (p. 23, 2015) en algunos países, las plazas docentes creadas para sustentar los aumentos de cobertura han sido ocupadas con porcentajes significativos de profesores sin la formación profesional y pedagógica requerida para garantizar el logro de los aprendizajes esperados. Si este porcentaje se mantiene para los próximos años, se hablaría entonces de que sólo 59.606 millones de los profesores serían capacitados, 4.685 millones de Latinoamérica. Si tomáramos en consideración los estadísticos de la Organización para la Cooperación y el Desarrollo Económico (OECD), el promedio de alumnos por profesor a nivel primaria es de 21 y en secundaria es de 23 . Es decir, que más de 200 millones de estudiantes se verían afectados a nivel mundial y más de 20 millones en Latinoamérica (OECD, 2019).

En su Proyecto de Estrategia a Plazo Medio 2014-2021, la UNESCO declara apremiante el subsanar la enorme penuria de docentes cualificados como estrategia esencial para mejorar la calidad de la educación y promover las tecnologías de la información y la comunicación (TIC) y nuevas modalidades de aprendizaje interactivo para mejorar el acceso al conocimiento, facilitar su difusión y lograr un aprendizaje más eficaz a lo largo de toda la vida (Llivina y Urrutia, 2017, p.3); estableciendo como objetivo cardinal el formar bien a los docentes, tanto antes de empezar a impartir clase como durante su trayectoria profesional, siendo que la formación no debe interrumpirse una vez que estos comienzan a trabajar en las escuelas; estando siempre presente

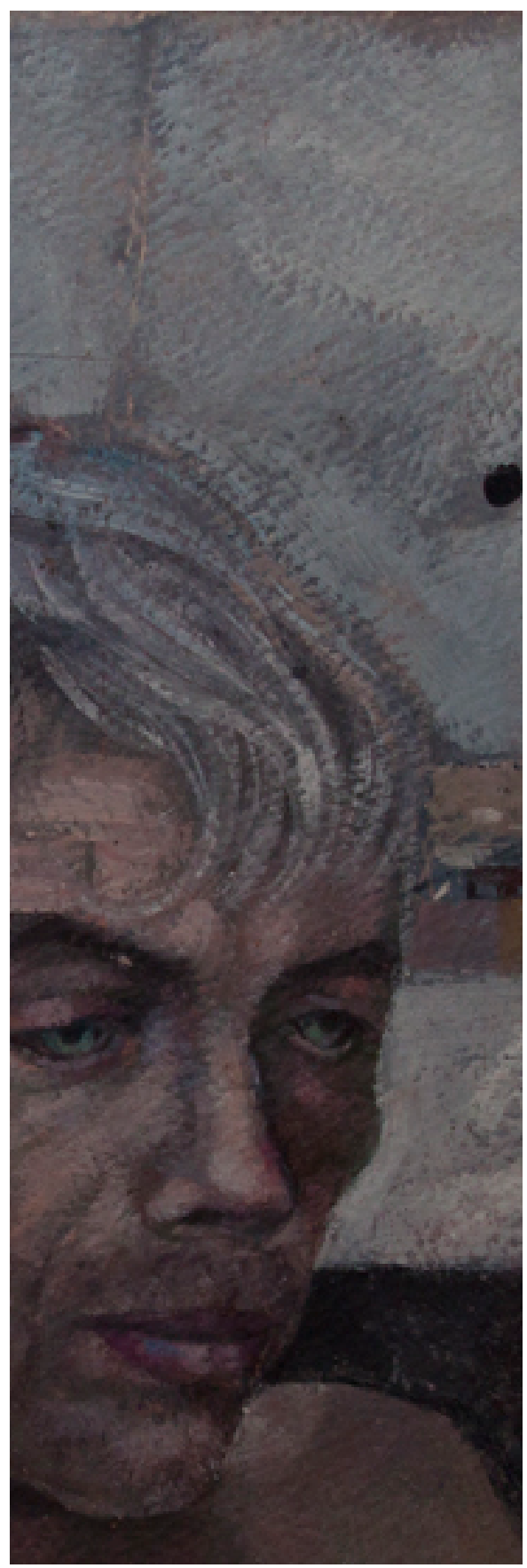

UNESCO (p. 23, 2015) "en algunos países, las plazas docentes creadas para sustentar los aumentos de cobertura han sido ocupadas con porcentajes significativos de profesores sin la formación profesional y pedagógica requerida para garantizar el logro de los aprendizajes esperados". 


\section{Los docentes latinoamericanos se auto adscriben a la clase media o media baja y se perciben como una profesión de bajas remuneraciones, con patrones de consumo cultural precarios.}

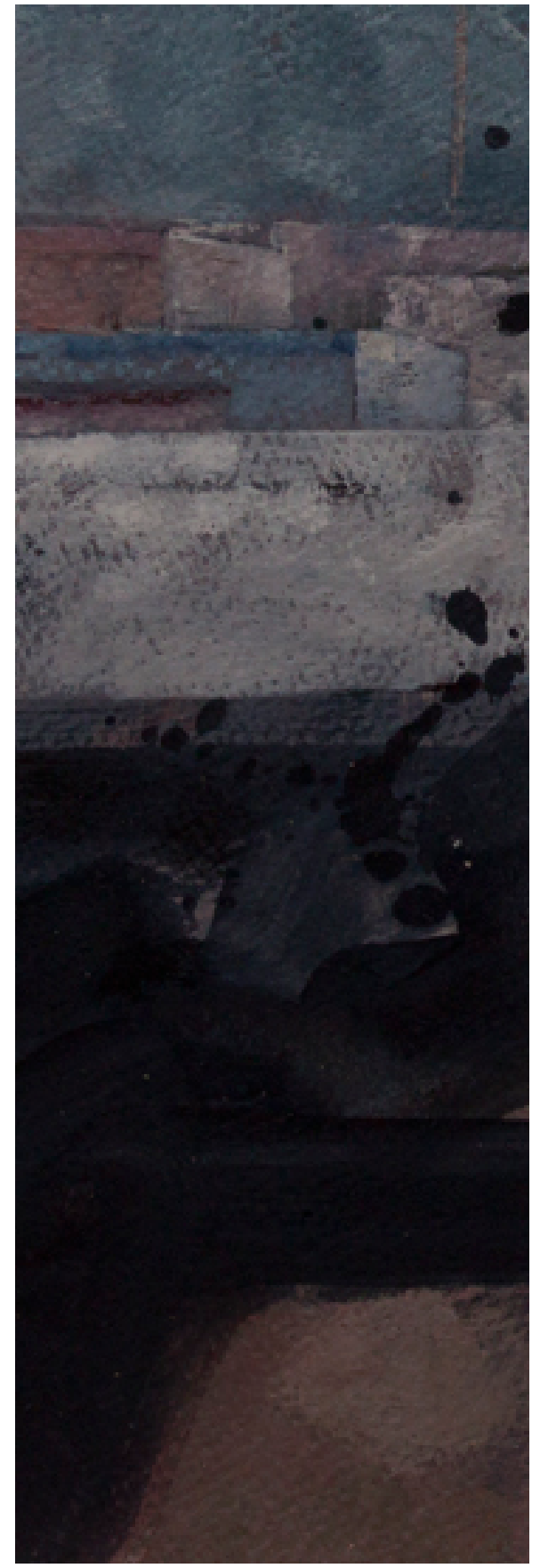

la necesidad de ideas innovadoras en materia de enseñanza-aprendizaje.

En objeto de ello, múltiples organizaciones de carácter mundial, explican que la profesionalización y capacitación del personal docente, directivo y de supervisión, debería convertirse en una política inherente a un sistema educativo centrado en la calidad y la mejora continua, puesto que son los responsables de hacer factible dicha aspiración.

Sin embargo, un elemento a tomar en deferencia es el perfil descrito por Tenti, Ballelli y Valenzuela (citados en UNESCO 2015), quienes explican lo siguiente:

Los docentes latinoamericanos se auto adscriben a la clase media 0 media baja y se perciben como una profesión de bajas remuneraciones, con patrones de consumo cultural precarios, con un trabajo agobiante y sin el tiempo necesario para planificación, preparación de materiales, evaluación, superación profesional, trabajo en equipo, atención de estudiantes y sus familias, entre otras actividades adicionales a la enseñanza en el aula (p. 24).

En este sentido, la educación en línea a través de la incorporación de las TIC, se ha vuelto una de las opciones óptimas por las múltiples ventajas que represen- ta en cuanto a flexibilidad y conveniencia, particularmente para aquellos que no precisan del tiempo para instruirse de manera presencial en múltiples nociones, o consolidar las ya adquiridas, destacando en este género los cursos en línea. Senderos pedagógicos que al dar respuesta a la necesidad de adaptabilidad que demanda la sociedad de hoy en día, y portabilidad por su propiedad de acceder desde prácticamente cualquier dispositivo, proporcionando un sentido de ubicuidad, coadyuvan en el aprendizaje de un amplio abanico de conocimientos complementarios, brindando al alumnado la oportunidad de acceso libre y gratuito a estas valiosas plataformas a modo de acceder a contenidos docentes anteriormente impartidos como parte de una educación formal. Motivo por el cual, se vuelve necesario evaluar la efectividad de estos recursos como instrumentos adjuntos a una preparación inicial y continua a fin de combatir el rezago y extender la cobertura, dado que optar por la Educación a Distancia (EaD) representa una alternancia óptima frente a las barreras de una formación convencional, particularmente en términos de ingreso y permanencia.

\section{PLANTEAMIENTO DEL PROBLEMA}

Empero la temática de desarrollo profesional docente data de tiempo atrás, aún no existe una amplia cantidad de estu- 


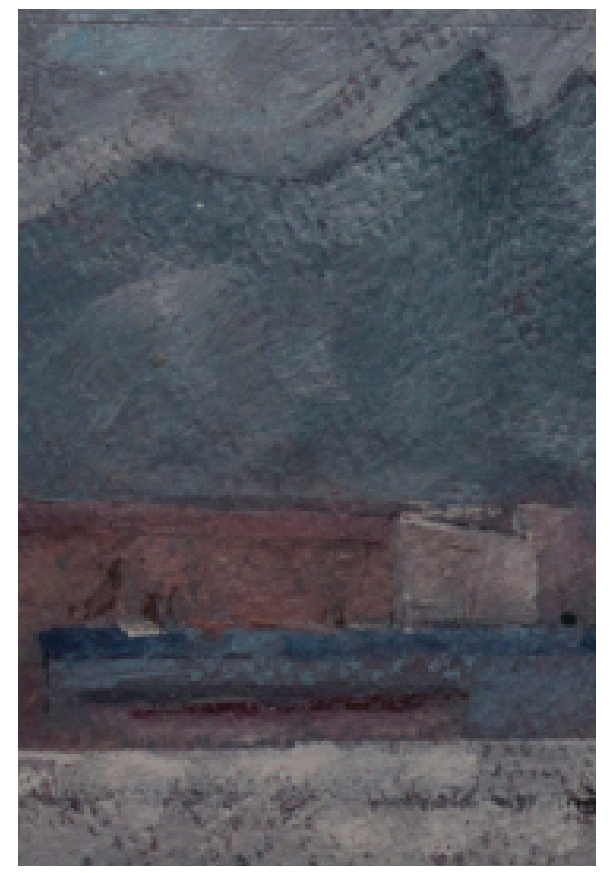

dios que proporcionen evidencia sobre el análisis de la eficacia correspondiente a los programas de formación continua en línea para este grupo de interés. Al respecto Gárate y Cordero (2018) explican lo siguiente:

Si bien la formación contínua en línea de profesores surge como un recurso que brinhda herramientas para el desarrollo docente, además de propiciar la adquisición de habilidades digitales para el uso y manejo de nuevas tecnologías, mismas que son requeridas para incidir en el aprendizaje de los estudiantes del siglo XXI, aún no hay un número suficiente de investigaciones que proporcionen evidencia contundente sobre el éxito de los programas de formación continua en línea para docentes (p.12).

Los cursos en línea son herramientas capaces de coadyuvar en la formación docente en términos adaptativos y flexibles para el logro de un Aprendizaje a lo Largo de la Vida (ALV) como parte de la Sociedad de la Información y Comunicación (SIC), siendo ésta una de las metas derivadas del ODS 4 como parte

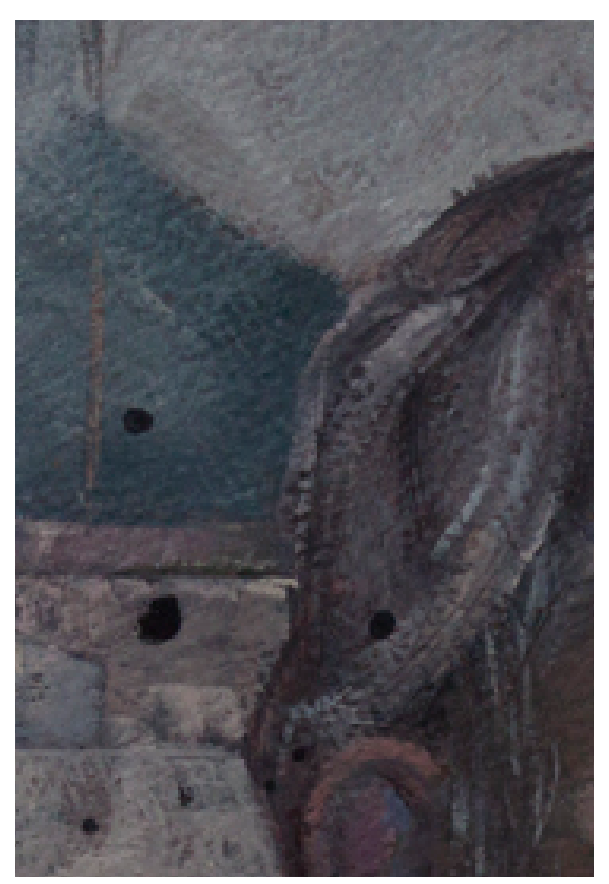

de la Agenda 2030 de Latinoamérica. Los cursos en línea son considerados un recurso educativo capaz de posibilitar la creación de un entorno virtual de interacción y desarrollo. Dados sus principios de ubicuidad y masividad, proponen una variante a los tradicionales escenarios de enseñanza-aprendizaje, con la ventaja de mantener una mayor cobertura, superando la necesidad de un aula como único espacio, en menester de una adquisición de conocimientos en términos de flexibilidad. En consideración a ello, Gómez y Ortega (citados en Gómez, 2017) explican cómo estos cursos, debido a su interactividad, se presentan a nivel mundial como el recurso formativo del siglo XXI y de la SIC.

Según estudios del MIT, cuando estos cursos caracterizados por ser masivos, abiertos y en línea son gratuitos, complementarios y opcionales generalmente como MOOC (Massive Open Online Courses), las tasas de finalización rondan entre el $4 \%$ y el $10 \%$, y cada año decrece un tanto más. En el 2015 el índice fue del 6\%; en el 2016 del $4 \%$ y en el 2018 del 3\% (Lederman, 2019; Reich y Ruipérez,

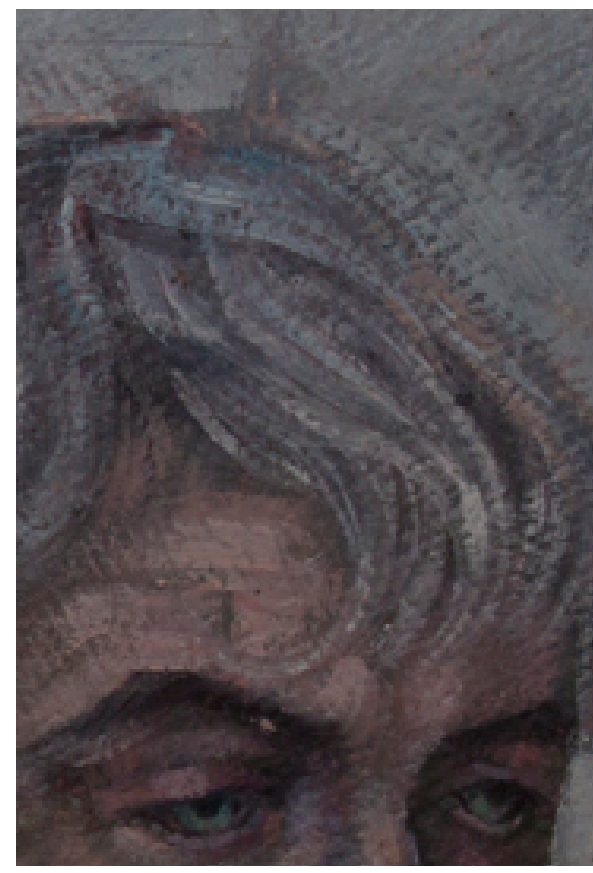

2019). Razón por la cual, se vuelve apremiante evaluar la efectividad de este tipo de propuestas formativas.

\section{OBJETIVO GENERAL \\ DE LA INVESTIGACIÓN}

El propósito del proyecto, además de promover la formación y el desarrollo profesional docente a través del diseño, implementación y evaluación de un E-Course de gestión educativa para el desarrollo de profesionales de la educación, es analizar los resultados obtenidos de dicha propuesta en términos de eficacia, considerando los porcentajes de participación, eficiencia terminal, aprobación, deserción, y grado de satisfacción del curso correspondiente.

Como parte de la implementación del curso, se busca adicionalmente la promoción y el uso de las TIC para la formación de profesionales de la educación en etapas inicial y continua, en función de contribuir en el ODS 4 de la Agenda 2030 de Desarrollo Sostenible, focalizando esfuerzos en el cumplimiento de la meta 4.c, centrada en aumentar sustancialmente para el año 2030, la oferta 
de profesores calificados mediante una red de cooperación internacional.

En virtud de esto, se tiene planteado el siguiente objetivo central de investigación: Analizar la eficacia generada al diseñar e implementar un E-Course de gestión educativa como una herramienta complementaria de formación para el desarrollo de profesionales de la educación.

\section{OBJETIVOS ESPECÍFICOS DE LA INVESTIGACIÓN}

El objetivo específico de la presente investigación es: Determinar el porcentaje de ingreso, de participación, de aprobación, de culminación y el grado de satisfacción en el E-Course de gestión educativa.

\section{HIPÓTESIS}

En consideración de lo anterior, se plantean las siguientes hipótesis descriptivas, las cuales según Hernández, et al., (2014) Son utilizadas en estudios descriptivos, para intentar predecir un dato o valor en una o más variables que se van a medir u observar (p. 108).

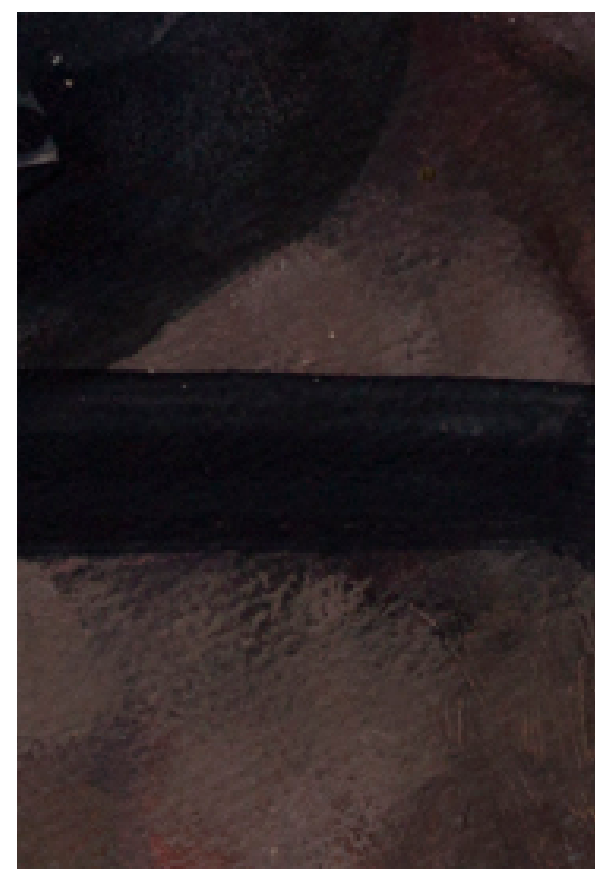

- H1: La eficacia del E-Course en función de los indicadores de ingreso, participación aprobación, culminación y evaluación de satisfacción; será superior al $70 \%$.

- HO: La eficacia del E-Course en función de los indicadores de ingreso, participación aprobación, culminación y evaluación de satisfacción; no será superior al $70 \%$.

\section{JUSTIFICACIÓN \\ DE LA INVESTIGACIÓN}

El apremio que demanda esta temática de interés, reside en que la formación y capacitación de los docentes están estrechamente ligadas al logro educativo. Con relación a ello Irina Bokova, exdirectora general de la UNESCO explica que Un sistema educativo es apenas tan bueno como sus docentes. Liberar su potencial es esencial para mejorar la calidad del aprendizaje. Todo indica que la calidad de la educación mejora cuando se apoya a los docentes y se deteriora en caso contrario, lo que contribuye a los alarmantes niveles de analfabetismo. (UNESCO, 2014, p. 9). Por ejemplo, un análisis del estudio TIMSS 2011 reali-

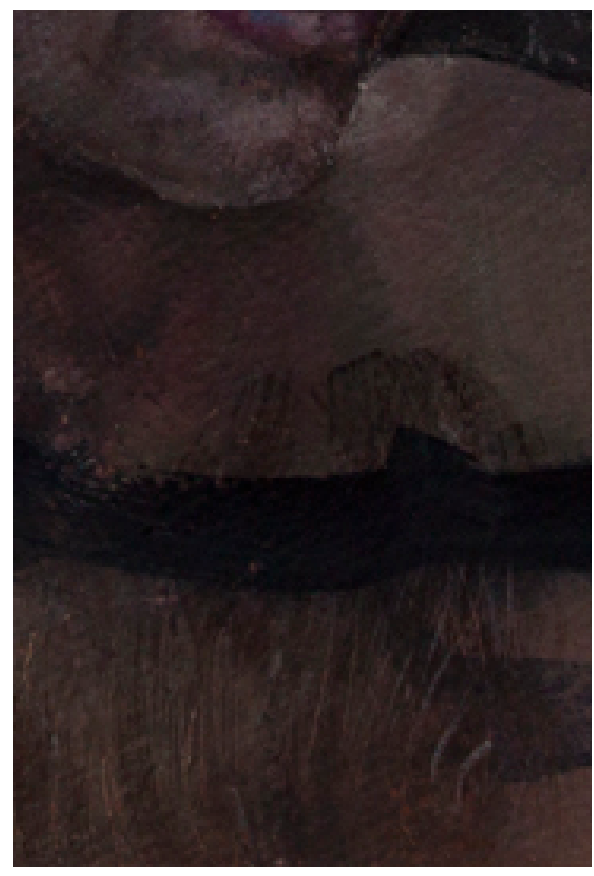

zado por el International Association for the Evaluation of Educational Achievement (IEA) e implementado en niños de cuarto grado de 45 países, reveló que en todos ellos, cuanto mayor era la calidad de los docentes, menor era la incidencia del bajo rendimiento en los estudiantes (IEA, 2012). Es decir, la calidad de un sistema educativo, se sustenta en la preparación del profesorado; la cual a su vez mantiene un mayor alcance, siendo que el impacto derivado de dichos factores, trasciende a nivel social a través de del desarrollo individual, resultado de una educación de calidad, impactando subsecuentemente en el crecimiento económico de la región.

Para Latinoamérica, este elemento se encuentra delimitado principalmente por sus flaquezas formativas, tanto en etapa inicial como continua, dado a que la formación antes del servicio no puede visualizarse como un evento aislado sino más bien, como el comienzo de un desarrollo profesional permanente (Miller, citado en Núñez, et al., 2012). Al respecto, Pérez, et al. (2015, p. 116) explica que El desarrollo profesional docente

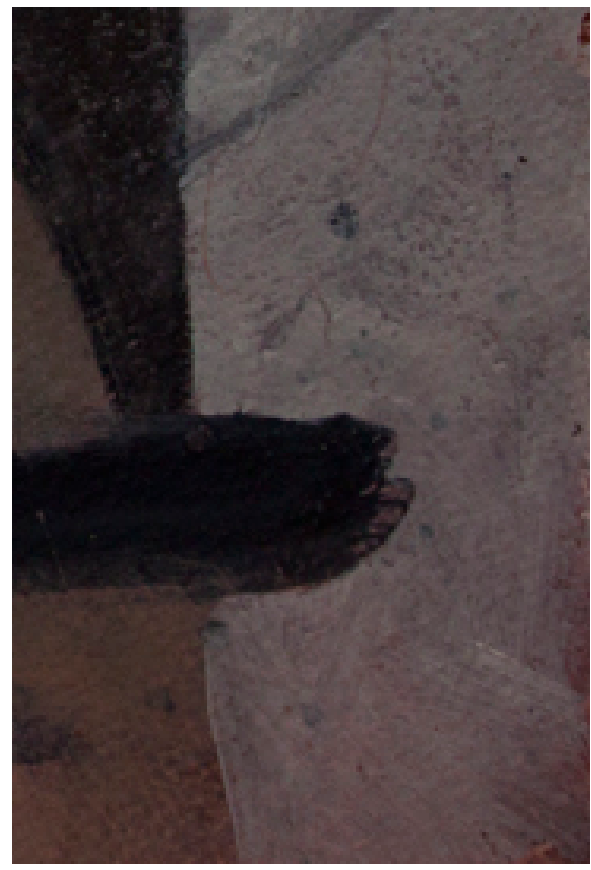




\section{En el contexto actual, la formación ha de tener en cuenta las preeminencias que ofrece la tecnología y su impacto en los procesos de aprendizaje.}

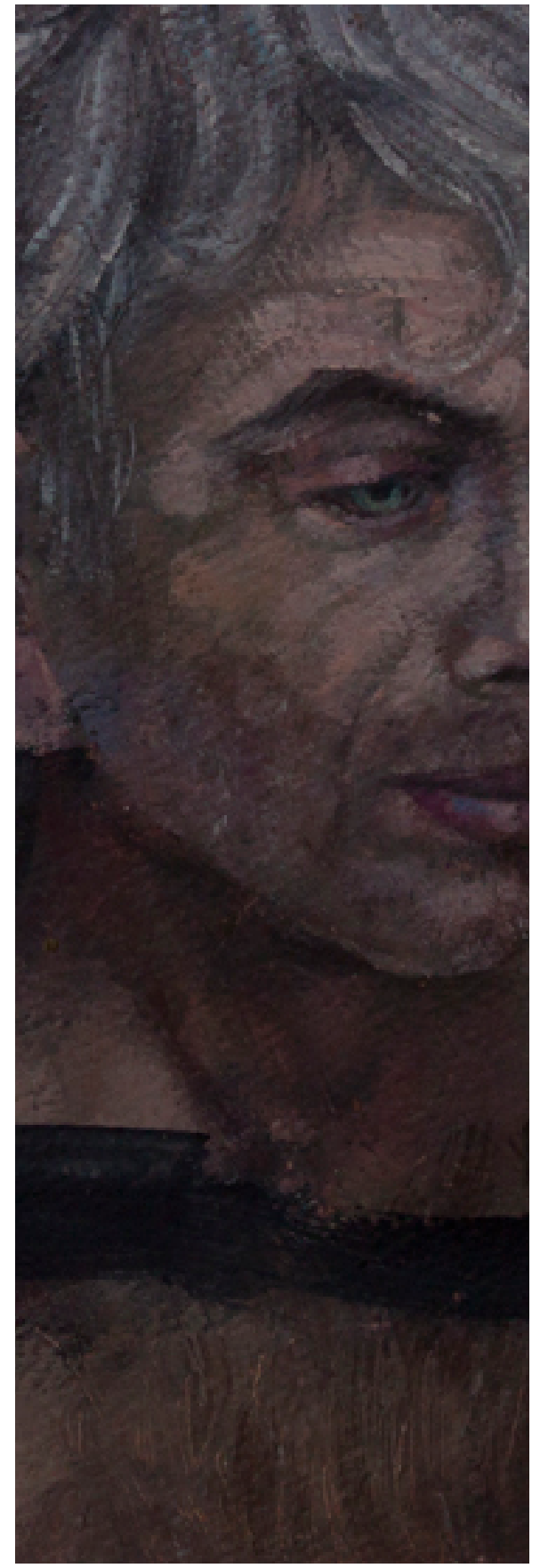

se concibe como un proceso continuo de aprendizaje que comprende tanto la preparación formal de los docentes como otras influencias sobre qué y cómo aprenden las competencias profesionales para el desempeño de su práctica que abarca la formación inicial, la inducción o inserción laboral y la formación continua. En este sentido, la formación debe concebirse como el inicio de una trayectoria de desarrollo profesional que prosigue con la formación en el servicio (Sánchez y Jara, 2018).

En consideración de lo anterior, la educación no debe ser concebida como un período; siendo que no basta optar por una educación extensa, es decir una prolongación de la educación académica durante la vida adulta, sino recurrir a una educación continua 0 permanente de desarrollo individual recibida a largo de la vida, presentando una continuidad espacial no limitada al espacio físico de una escuela. Esta necesidad, según explica Torres (1995) deriva de una serie de factores:

1. El constante aumento del conocimiento.

2. La renovación acelerada del conocimiento para evitar la obsolescencia de lo aprendido.

3. Las modificaciones estructurales, resultado de los nuevos avances tecnológicos.
4. La confrontación de las diferencias entre el nivel de expectativas por parte del estudiante y la capacidad de satisfacerlas.

En el contexto actual, la formación ha de tener en cuenta las preeminencias que ofrece la tecnología y su impacto en los procesos de aprendizaje. Al ser parte de una sociedad en red, el aprendizaje no se desarrolla hoy en día de forma lineal, ni en espacios concretos; por lo que las instituciones formales han dejado de representar el único lugar para aprender, así es que los programas de educación no formales han llegado a tomar protagonismo.

La educación virtual permitiría alcanzar objetivos que hasta aquí han estado fuera del alcance de la empresa educativa: poner a disposición de todos, de manera accesible, toda la información y el conocimiento disponibles; facilitar que los alumnos lo absorban de acuerdo con necesidades y capacidades y en función del conocimiento previamente adquirido; y que lo hagan de la manera y de acuerdo a las formas de inteligencia que mejor les permitan avanzar (Brunner 2000, p. 34).

\section{MARCO TEÓRICO}

El e-learning es un concepto adoptado inicialmente por las empresas privadas 
orientadas a la oferta de formación continua (Area, et al, 2009), que ha logrado integrarse como parte de una educación formal y no formal de manera presencial y a distancia en ámbitos educativos y de negocios como parte de un proceso de desarrollo profesional. Esta modalidad de aprendizaje dirigida principalmente a sujetos geográicamente dispersos que, en función de su disponibilidad, interactúan en tiempos dispares a través de recursos tecnológicos (Olivas, 2018), con el paso del tiempo ha sido asociada con otro concepto referente al ámbito organización, la gestión del conocimiento; esto como parte de un proceso de formación en etapas inicial y contínua. Si bien, ésta mantiene un nexo altamente estrecho con la educación a distancia, la versatilidad que la caracteriza, permite su incorporación a fin de acrecentar la calidad de los procesos de aprendizaje, por lo general a través de recursos educativos distribuidos en la red.

En los modelos de educación a distancia, particularmente en el diseño de cursos virtuales en modalidad sincrónica 0 asincrónica, se requiere un mayor énfasis en la etapa inicial de planificación, siendo un proceso más exhaustivo. El entorno instruccional debe vislumbrarse como un sistema interrelacionado por una serie de componentes, destacando entre estos: los contenidos y materiales, las es- trategias, los medios o tecnologías y los participantes.

De acuerdo con Broderick (citado en Roger Williams University, 2020, párr. 1) El diseño instruccional es el arte y ciencia aplicada de crear un ambiente instruccional, junto con materiales claros y efectivos, que ayudarán al alumno a desarrollar la capacidad para lograr ciertas tareas. Según lo explican Belloch (2011) y Romero (2016) los modelos de diseño instruccional mantienen sus bases epistemológicas en las teorías del aprendizaje correspondientes a cada época.

Modelos DI de Primera Generación: En la época de 1960, estos modelos se caracterizaban por forjar su proceder en la Teoría Conductista, siendo lineales, sistemáticos y prescriptivos, enfocándose en los conocimientos y destrezas académicas, así como en los objetivos de aprendizaje observables y medibles.

Modelos DI de Segunda Generación: En la década de 1970, los modelos de DI se fundamentaban en la Teoría de sistemas y del procesamiento de la información, siendo más abiertos que los de primera generación al enfocarse más en el proceso que en el producto, instando por la participación de los alumnos en consideración de aspectos internos y externos a la instrucción.

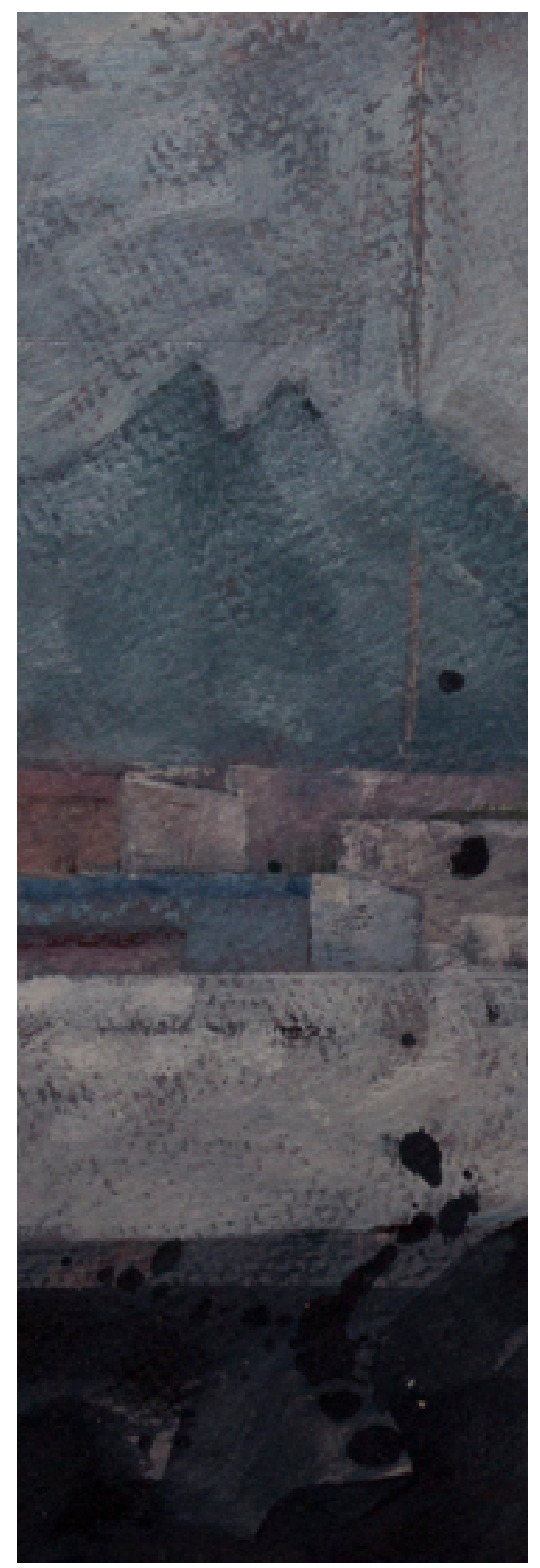

\section{En los modelos de educación a distancia, particularmente en el diseño de cursos virtuales en modalidad sincrónica o asincrónica, se requiere un mayor énfasis en la etapa inicial de planificación, siendo un proceso más exhaustivo.}


Modelos DI de Tercera Generación: En la década de 1980, se pasó a brindar un mayor enfoque a la Teoría cognitiva, la cual pretende comprender los procesos de aprendizaje, haciendo énfasis en el pensamiento, la solución de problemas, el lenguaje, la generación de conceptos y el procesamiento de la información.

Modelos DI de Cuarta Generación: A partir de 1990 y hasta la fecha estos se fundamentan en la Teoría constructivista, en la Teoría de sistema y en la Teoría del caos, generando un modelo heurístico que subraya el rol activo de los participantes, más que en los contenidos.

Dado que el DI mediado por la tecnología demanda un análisis crítico sobre las estrategias y medios óptimos para el logro de los objetivos planteados, es crucial que éste mantenga un sustento pedagógico, el cual, acorde a Álvarez, et al. (2016) se desarrolla en dirección de 4 panoramas:

- La acción pedagógica: La cual focaliza sus esfuerzos hacia el logro de una intención educacional llamada objetivo de aprendizaje, tomando

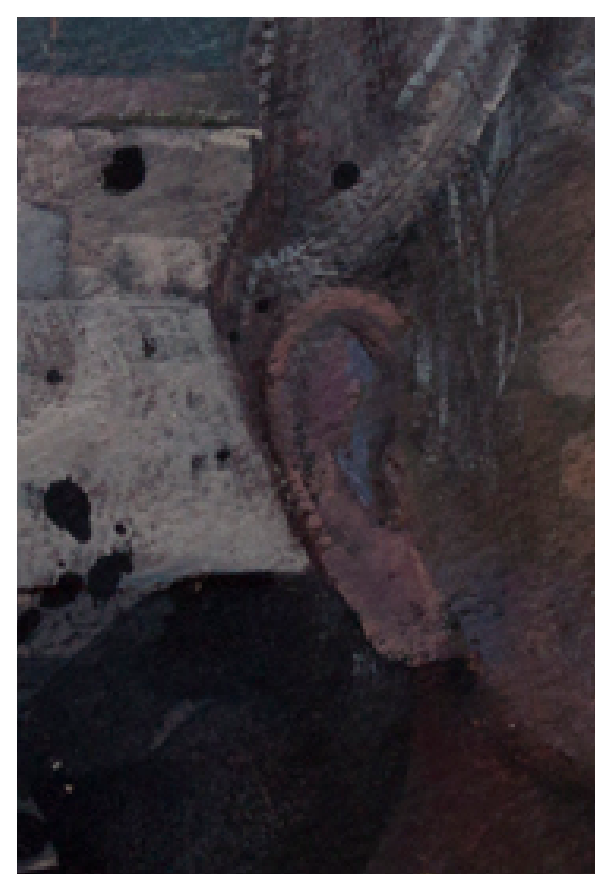

Presencia Universitaria

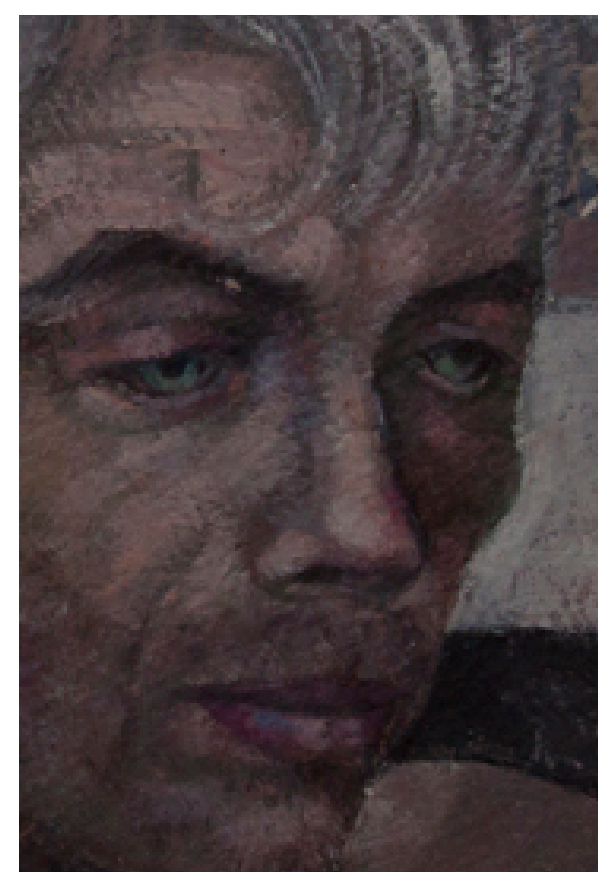

como punto de inicio al sujeto, es decir, el perfil del participante, y lo que se desea lograr en él haciendo énfasis particularmente en las competencias a desarrollar al transmitir determinado elemento simbólico denominado conocimiento a través de la comunicación, haciendo uso de recursos educativos.

- $\quad$ Las teorías de aprendizaje: Siendo diferentes a las teorías de instrucción, ya que éstas como bien explica Umaña (2008) determinan los procesos de aprendizaje, en tanto que las teorías de instrucción fungen como un soporte para la construcción del aprendizaje, para lo cual es importante considerar la taxonomía de Zubiría (2006), la cual identifica 3 modelos pedagógicos:

1. Heteroestructurantes: Incluyen el conductismo, el conexionismo, el condicionamiento operante y la enseñanza programada; teorías en las cuales el usuario percibe acompañamiento, motivación y retroalimentación. En entornos virtuales de aprendizaje esto incluye el diseño de guías de ayuda para la navegación

52 dentro del curso, la autoevaluación y actividades de repetición.

2. Autoestructurantes: Aquí entra el cognitivismo, el constructivismo, el constructivismo social y la modificabilidad cognitiva estructural; teorías que facilitan el autoestudio y la autoconstrucción del conocimiento. En EVA, esto incluye el diseño de actividades basadas en la resolución de problemas y el trabajo colaborativo en la virtualidad, como por ejemplo wikis, foros de discusión y blogs.

3. Interestructurantes: Éstos consideran la conversación didáctica mediada, el diálogo didáctico mediado, la pedagogía dialogante, el aprendizaje en red y conexionismo; sosteniendo que el aprendizaje es un proceso que debe darse de forma activa a fin de desarrollar la cognición, entrando elementos socio-afectivos y prácticos mediante el uso de la tecnología. En EVA algunos ejemplos de aplicación son el uso de las redes sociales y recursos de internet externos a la plataforma utilizada, que favorezcan la autogestión del aprendizaje.

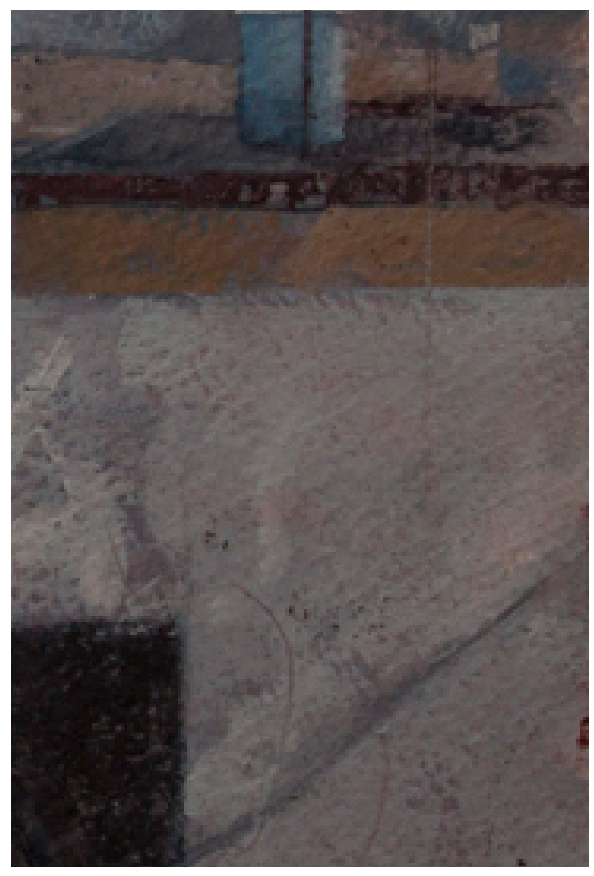




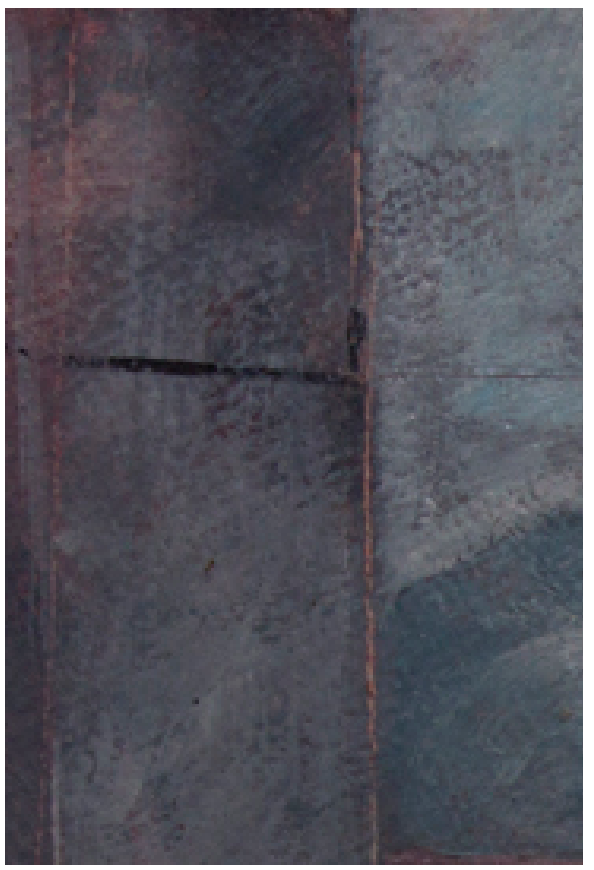

- Los modelos de diseño instruccional: ADDIE, Jonassen, DPIPE, Gagné y Briggs, Dick y Carey, por mencionar algunos.

- Las TIC: Integrándolas como parte del funcionamiento del curso.

Considerando lo anteriormente planteado, el presente estudio fue diseñado con base en el Modelo DPIPE de Miratía y López (2007), y consta de 5 etapas:

1. Diseño: que toma en consideración objetivos, audiencia, contenidos, evaluación, materiales estrategias didácticas y recursos.

2. Producción: enfocado al diseño de la plataforma virtual en la cual sería alojado el curso.

3. Implementación: que incluye montaje de los contenidos en la plataforma, la cual estará ubicada en un servidor.

4. Publicación: haciendo referencia a la difusión del curso.

5. Evaluación: valoración del proceso de enseñanza y aprendizaje.

El impacto de los estilos de aprendizaje en el diseño de los cursos ya sea en mo-

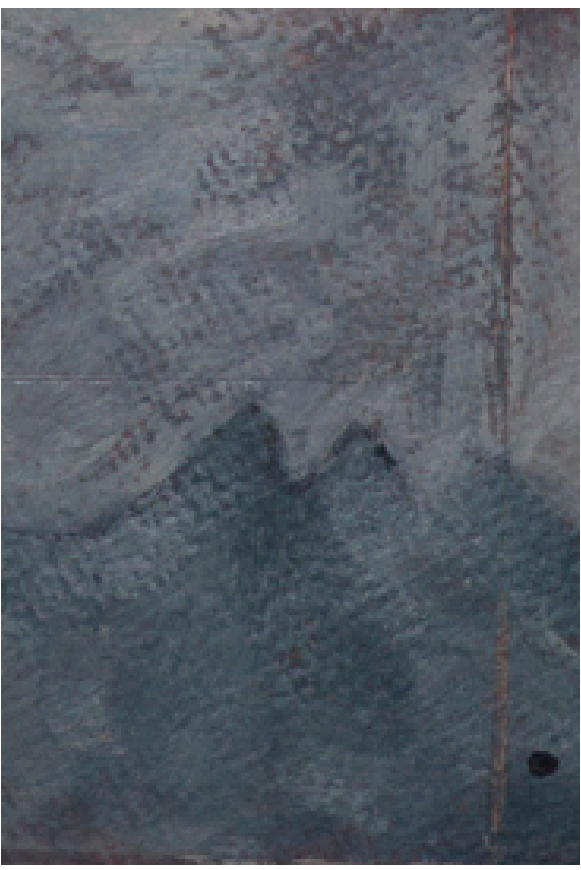

dalidad presencial, online (a distancia) 0 en blended learning (híbrido o combinado), debe tenerse en cuenta como un factor clave para mejorar el desempeño académico, considerando las preferencias cognitivas y orientaciones psicológicas más comunes del educando.

Este estudio se centrará en el Modelo VARK Neil Fleming y Collen Mills, el cual según explican González, et al. (2012), funge como un modelo idóneo para el diseño de cursos en línea. Su enfoque reside en la representación de la información y la preferencia sensorial del educando para procesarla de forma más sencilla, combinando 2 elementos: la percepción y la memoria, surgiendo en consideración los siguientes perfiles:

- Visual: Comprende mejor los contenidos a través de ilustraciones visuales, como imágenes, diagramas, videos y folletos; ya que le permite relacionarlos con ideas o conceptos previos. Toma en cuenta las formas, tamaños, distancias, colores y otras características físicas; prefiere tomar notas.

- Auditivo: Recuerda más fácilmente

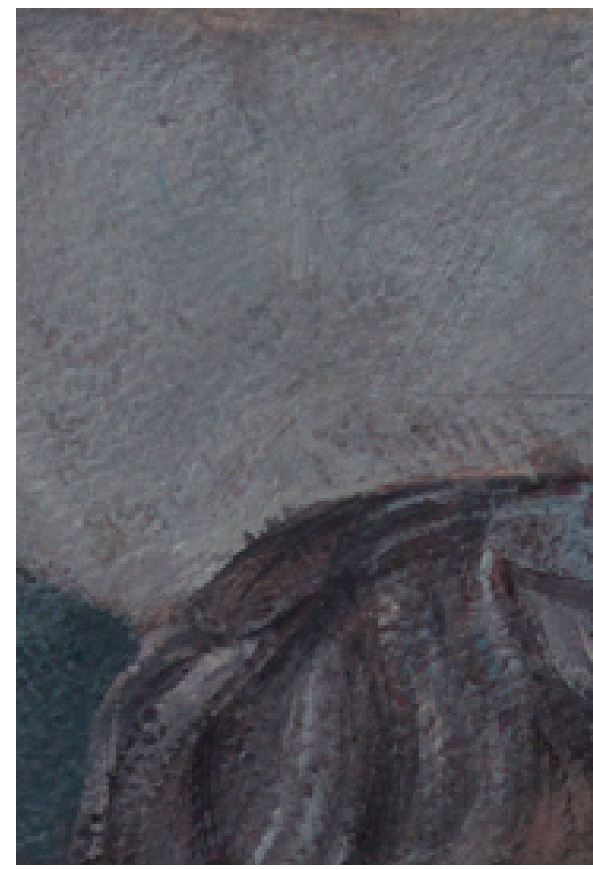

la información si ésta es abordada durante una explicación oral. Considera el tono de voz, el volumen, timbre, pausas, tempo y otros matices. Aprende mejor a través de conversaciones, es decir hablando y escuchando. Le gusta leer en voz alta y utilizar grabaciones, ya que para él un texto puede tener poco significado hasta que lo escucha.

- Lector/Escritor: Presenta una mayor capacidad para codificar y comprender mensajes a través de textos 0 lecturas.

- Kinestésico: Asimila de manera óptima los datos a través de un enfoque de manipulación, examinando el mundo físico que les rodea. Le es difícil permanecer sentado durante periodos largos y suele distraerse fácilmente a causa de su necesidad por explorar. Permanece atento a las sensaciones y movimientos, lo que genera un aprendizaje más profundo y difícil de olvidar (Fleming y Baume, 2006).

Esta propuesta sustenta sus bases en el Modelo de Programación Neurolingüísti- 
ca de Richard Bandler y John Grinder, el cual sostiene que el estilo de aprendizaje de cada individuo dimana de su Programación Neuro Lingüistica (PNL) o de la manera en la cual muestra una mayor facilidad para captar, recordar, imaginar o enseñar un contenido determinado, siendo el canal perceptual por donde se apropia de los contenidos.

\section{MÉTODO}

Selección de la muestra

(descripción):

La población bajo la cual se centra este estudio comprende todos los alumnos de Licenciatura en Educación y docentes iberoamericanos que pertenecen a las 31 instituciones de educación superior participantes ubicadas en los 16 países considerados, incluyendo: Bolivia, Brasil, Chile, Colombia, Cuba, Ecuador, España, México, Nicaragua, Panamá, Paraguay, Perú, Portugal, República Dominicana, Uruguay y Venezuela, siendo éstas copartícipes de la Red AGE, organización sin fines de lucro que impulsa la temática bajo la cual se centra el curso a implementar. Para la selección de los sujetos bajo estudio, se recurrió a un muestreo no probabilístico voluntario.

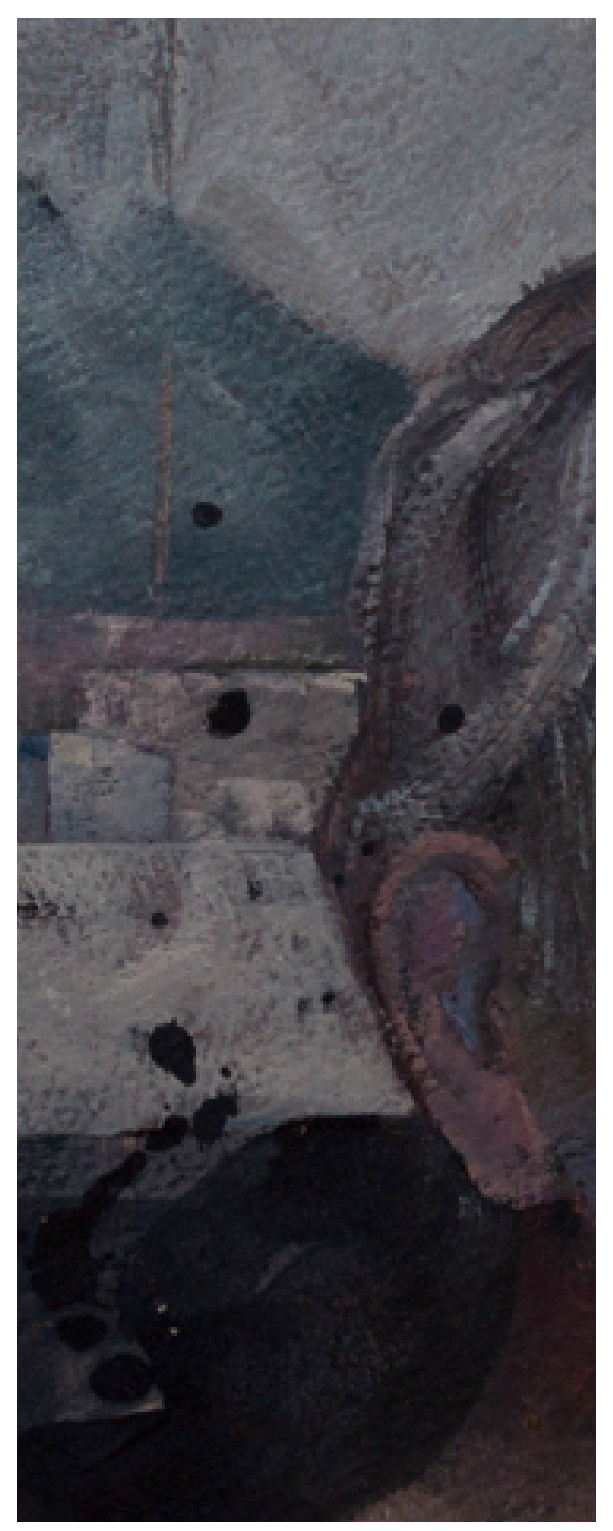

La muestra consta de 256 participantes de 20 IES provenientes de 14 países incluyendo: Argentina, Bolivia, Brasil, Chile, Colombia, Cuba, Ecuador, España, México, Nicaragua, Panamá, Paraguay, Perú, y Uruguay. No obstante, únicamente el $82,4 \%$ de los inscritos, que equivalen a 211 participantes, autorizó el uso de datos no sensibles para investigaciones educativas derivadas. De los 211 participantes inscritos, 139 son mujeres $(65,9 \%)$, y el $34,1 \%$ hombres.

\section{Instrumento de Investigación:}

Como técnica de recolección de datos aplicados se recurrió a la encuesta por medio del uso de cuestionarios como instrumento y fuente primaria de información cuantitativa y cualitativa, constando de un conjunto de preguntas de tipología variada, preparadas sistemáticamente para conocer o evaluar al grupo representativo de estudio.

Las preguntas empleadas fueron de tipo abierto y cerrado. Las preguntas cerradas se formularon en diferentes formatos: de opción múltiple, dicotómicas y de escalas Likert, siendo estas últimas de escalamiento simétrico y neutral.

Tabla 1. Resultados preliminares

\begin{tabular}{|c|c|c|}
\hline Progreso & Participantes & $\begin{array}{c}\text { \% con respecto a los participantes } \\
\text { preinscritos }\end{array}$ \\
\hline Inscripción & 211 & $100 \%$ \\
\hline Ingreso a plataforma virtual & 150 & $71 \%$ \\
\hline Participación & 127 & $60 \%$ \\
\hline Acreditación & 99 & $47 \%$ \\
\hline Finalización de la última actividad & 89 & $42 \%$ \\
\hline
\end{tabular}




\section{Encuesta inicial}

(de datos generales):

- Objetivo: Recabar información distintiva de la muestra, tales como datos de identificación y antecedentes, incluyendo estilo de aprendizaje, vivencias en educación en línea y experiencias previas en cursos en línea, motivaciones, y opiniones referentes a la estructura de un curso con estas características; con lo cual se podrá tomar en consideración las preferencias y futuras propuestas.

- Cantidad de ítems: 15 en total, 3 preguntas abiertas, 5 de carácter dicotómico y 7 de opción múltiple.

\section{Encuesta de satisfacción} y retroalimentación:

- Objetivo: Conocer la opinión de los participantes referente al curso en línea, a modo de obtener una retroalimentación con base a su grado de satisfacción.

- Cantidad de ítems: 26 en total, 25 de tipo Likert y una abierta para la recepción de la retroalimentación correspondiente.

\section{Procedimiento:}

Para la inscripción de los participantes se diseñó una encuesta inicial, estructurada a modo de formato digital de registro en el sitio del Instituto de Investigación, Innovación y Estudios de Posgrado para la Educación (IIIEPE), institución cuyo apoyo ha sido crucial para el desarrollo de la presente investigación. La solicitud de inscripción contaba con ítems cerrados de perfilación para la recopilación de datos personales como género, edad, país de procedencia, rol que mantiene el participante en el contexto educativo, y último grado de estudios; así como antecedentes en el dominio de la tecnología y los cursos virtuales. En tanto que para evaluar la satisfacción del curso la encuesta implementada se consideraron 2 elementos:

- Calidad pedagógica: La cual considera la evaluación general del programa, el contenido temático, y las actividades y foros de discusión.

- Calidad técnica: Que incluye el diseño y la navegabilidad en la plataforma.

\section{RESULTADOS}

La estadía de los participantes se analizó con base en 5 etapas: 1) Su inscripción al curso, considerando la utilización de datos no sensibles, 2) su ingreso a la plataforma EVA IIIEPE, 3) su participación en las actividades, 4) su acreditación con una nota mínima aprobatoria de 70 , y 5) su participación en la última semana del curso, analizando particularmente la realización de la última actividad que compone el programa de formación; identificando los siguientes resultados (Ver Tabla 1).

\section{CONCLUSIONES}

Hasta el momento se ha logrado detectar porcentajes atípicos en los indicadores que muestra la literatura. Si bien los primeros cursos de esta índole parten del conectivismo, representando una modalidad masiva en cuanto a alumnos, con una estructura más abierta, sin la opción de evaluación ni un diseño instruccional previo; el curso desarrollado como parte del presente estudio, se basa en el constructivismo.

Zapata-Ros (2015) declara desde su perspectiva, que el punto débil de los cursos conectivistas es su propugnación por la espontaneidad en el proceso de enseñanza-aprendizaje y la ausencia de un diseño instruccional, elemento clave a considerar en la organización de cualquier programa formativo, puesto que lo ideal es que estos se apoyen En los avances de la moderna pedagogía, de las teorías del aprendizaje, de los modelos sobre cómo se aprende (p. 3). Según explica Margaryan, et al. (2015, p. 77) Los resultados indican que, aunque la mayoría de los M00Cs tienen buena envoltura, la calidad de su diseño instruccional es baja, siendo se parte desde situaciones casi de espontaneísmo pedagógico explícito; lo que afecta subsecuentemente la definición de objetivos, el diseño de las actividades, la selección de recursos y la evaluación.

A sabiendas que el curso implementado como parte del presente estudio, mantiene un enfoque constructivista y se ha estructurado desde el modelo de diseño instruccional DPIPE, se plantean los siguientes supuestos básicos:

- Los MOOC diseñados desde una concepción constructivista favorecen el incremento de los indicadores de desempeño de un e-Course tipo MOOC.

- El diseño instruccional favorece el incremento de los indicadores de desempeño de un e-Course tipo MOOC.

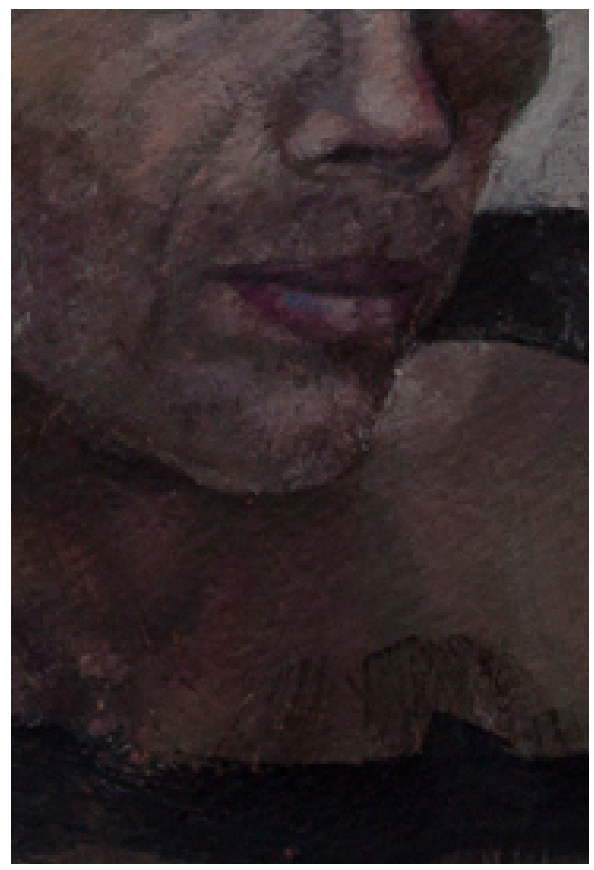




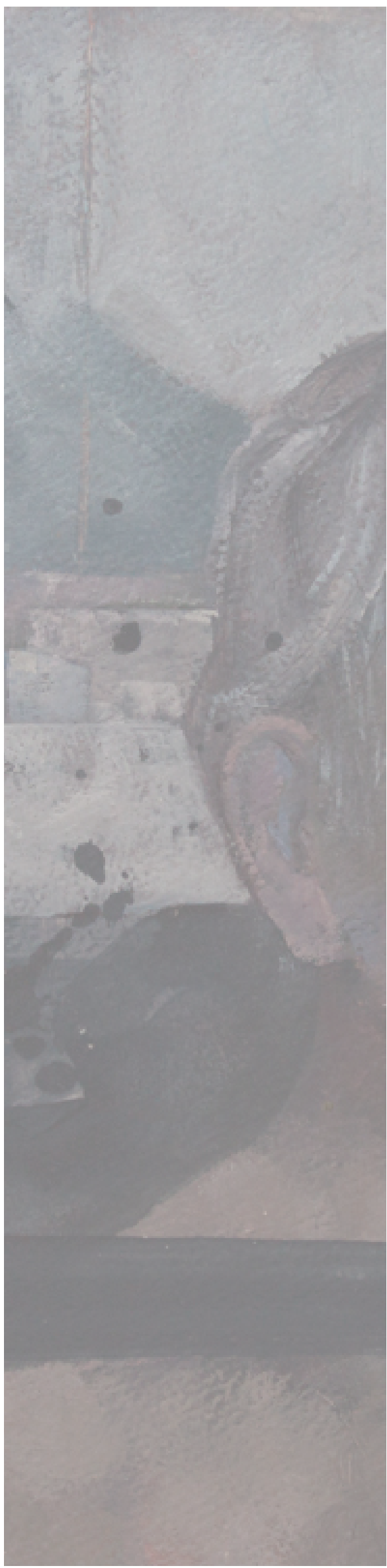

\section{REFERENCIAS}

Álvarez, E.Z., Murillo, M.C., Ramírez, A. (2016). Modelos de diseño instruccional mediados por tecnología en la capacitación empresarial. Revista Electrónica de Divulgación de la Investigación, 11 (1), 1-17. https://cutt. $\underline{\text { ly/7ggVNuN }}$

Area, M. y Ardell, J. (2009). E-Learning: Enseñar y aprender en espacios virtuales. En J., De Pablos (Coord). Tecnología Educativa. La formación del profesorado en la era de Internet, 391-424. Ediciones Aljibe. https:// www.researchgate.net/publication/216393113_E-Learning_ensenar_y_aprender_en_espacios virtuales

Belloch, C. (2011). Diseño instruccional. Universidad de Valencia. https://cutt.ly/oggVK44

Brunner, J.J. (2000). Educación: Escenarios de futuro. Nuevas tecnologías y sociedad de la información. OPREAL. https://cutt.ly/cggJOsx

Fleming, N. y Baume, D. (2006). Leaning Styles Agin: VARKing up the right tree. Educational Developments, $7(4), 4-7$.

Gárate, M. y Cordero, G. (2018). Apuntes para caracterizar la formación continua en línea de docentes. REXE. Revista de Estudios y Experiencias en Educación, 18(36), 2019-221. https://cutt.ly/ZggJYx8

Gómez, I. (2017). El MOOC como recurso para la adquisición de la competencia digital en la formación de los maestros de educación primaria. Revista de Tecnología de Información y Comunicación en Educación. Eduweb, 11(1), 77-88. https://cutt.ly/bggJUu0

González, B., Alonso, C. y Rangel, R. (2012). El Modelo VARK y el diseño de cursos en línea, Revista mexicana de Bachillerato a Distancia, 4 (8), 96-103. https://cutt.ly/WggVYmp

Hernández, R., Fernández, C. y Baptista, M.P. (2014). Metodología de la investigación (6a ed.). McGraw Hill. IEA (2012). TIMSS 2011. Marcos de la evaluación. International Study Center (IEA). https://cutt.ly/EggJORF Lederman, D. (2019). Why MOOCs Didn't Work, in 3 Data Points. Inside Higher Ed. https://cutt.ly/lggJAon

Llivina, M. y Urrutia, I. (2017). La formación docente de calidad para el desarrollo sostenible. Organización de las Naciones Unidas para la Educación, la Ciencia y la Cultura (UNESCO). https://cutt.ly/Dgg/Sco

Margaryan, A., Bianco, M. y Littlejohn, A. (2015). Instructional quality of Massive Open Online Courses (M00Cs). Computers \& Education, 80 (1), 77-83. https://cutt.ly/2ggXjP6

Miratía, 0. y López, M.G. (2007). Tecnología Instruccional y Educación a Distancia Modelo de Diseño de Cursos en Línea (DPIPE). Docencia Universitaria, 8(1), 115-130. https://cutt.ly/MggVA7q

Núñez, M., Arévalo, A., y Ávalos, B. (2012). Profesionalización docente: ¿Es posible un camino de convergencia para expertos y novatos? REDIE, 14 (2), 10-24. https://cutt.ly/cggJDne

OECD (2019). Indicator D2. What is the student-teacher ratio and how big are classes? Librería OECD. https:// cutt.ly/sggJGwn

Olivas, V. (2018). Tutorización de acciones formativas para el empleo. IC Editorial.

Pérez, A.I., Brouwer, N., Korthagen, F., Blanco, R., Vasquez, G., Molinari, A., Garant, C., Bourque, C. Favereau, M.S., Miranda, C., Arancibia, M., Gysling, J., López, P., Rivera, P. (2015). Formación continua y desarrollo profesional docente. Organización de Estados Iberoamericanos para la Educación, la Ciencia y la Cultura (OEI). Reich, J. y Ruipéprez, J. (2019). The MOOC pivot. Science, 363 (6423), 130-131. https://cutt.ly/yggJ29w

Roger Williams University (2020). About Instructional Design at Roger Williams University. RWU. https://cutt. Ly/5ggB2KD

Romero, N.A. (2016). Manual de diseño instruccional: Una propuesta con tareas integradoras (TI). UNED.

Sánchez, G.I. y Jara, X. E. (2018). De la formación inicial al trabajo docente: Comprensión de la trayectoria. Revista Educación, 42 (2), 1-20.

Torres, C. A. (1995). La política de la educación no formal en América Latina. Siglo veintiuno editores. https:// cutt.ly/vggJNX

UIS (2016). The world needs almost 69 million new teachers to reach the 2030 education goals. UNESCO Institute for Statistics. https://cutt.ly/OggJNhW

UIS (2019). Education: Percentage of trained teachers by teaching level of education.

UNESCO. Institute for Statistics. https://cutt.ly/RggJBdL

Umaña, A.C. (2008). Consideraciones pedagógicas para el diseño instruccional constructivista. UNED, 16 (1), 1-18. https://cutt.ly/PggV3c1

UNESCO (2014). Políticas docentes como desafío de Educación Para Todos más allá del 2015. Organización de las Naciones Unidas para la Educación, la Ciencia y la Cultura. https://cutt.ly/1ggJCN3

UNESCO (2015). Desglosar el Objetivo de Desarrollo Sostenible 4 Educación 2030. Organización de las Naciones Unidas para la Educación, la Ciencia y la Cultura.

Zapata-Ross (2015). El diseño instruccional de los MOOC y el de los nuevos cursos abiertos personalizados. Revista de Educación a Distancia, 45 (2), 1-35. https://cutt.ly/aggXdVP

Zubiría, J. (2006). Los modelos pedagógicos: hacia una pedagogía dialogante. Cooperativa Editorial Magisterio. 


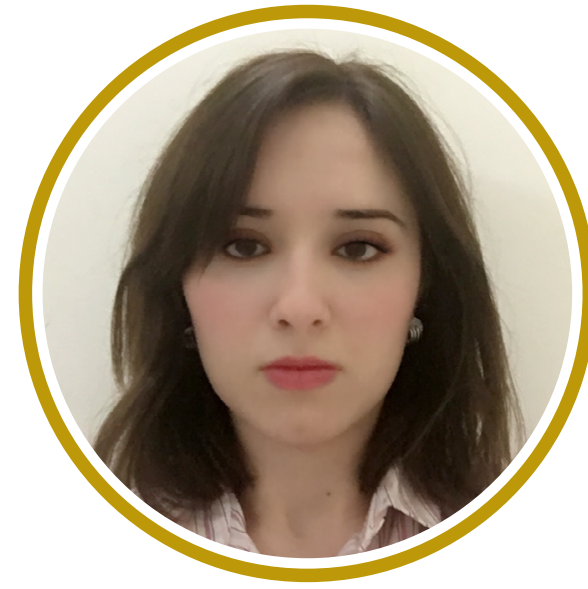

\section{Mariel \\ García Leal}

Ingeniera Industrial por la Universidad Tecmilenio, con Maestría en Administración de Negocios, Especialidad en Calidad y Productividad, y doctoranda de Educación con Acentuación en Tecnología Educativa. Es Investigadora Institucional del Instituto de Investigación, Innovación y Estudios de Posgrado para la Educación del Estado de Nuevo León (IIIEPE); y profesora asociada del Departamento de Ingeniería en la Universidad Tecmilenio.

\section{Correo Electrónico:}

mariel.garcia@iiiepe.edu.mx

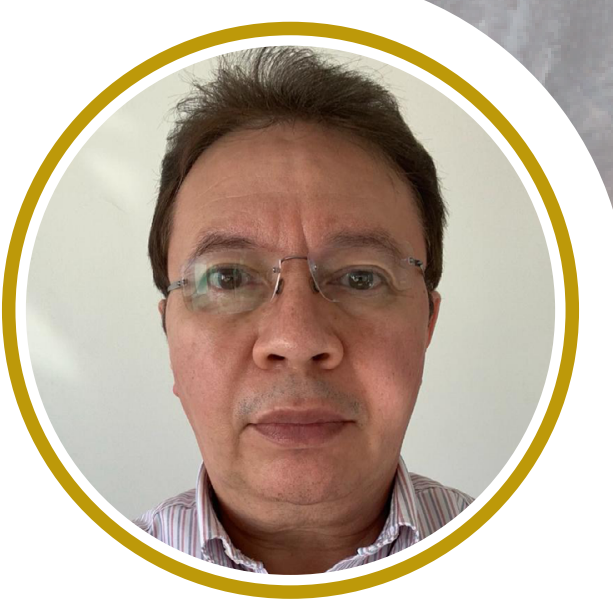

Hernán

\section{Medrano Rodríguez}

Profesor de Educación Primaria, Lic. en Educación Especial y Lic. en Derecho en México con Maestría en Innovación y Sistema Educativo y Doctorado en Pedagogía por la UAB, España. Ha sido profesor de educación primaria, educación especial, licenciatura, maestría y doctorado. Actualmente es Profesor en la Escuela de Ciencias de la Educación y Director General de Investigación en el IIIEPE.

\section{Correo Electrónico:}

hernan.medrano@iiiiepe.edu.mx 


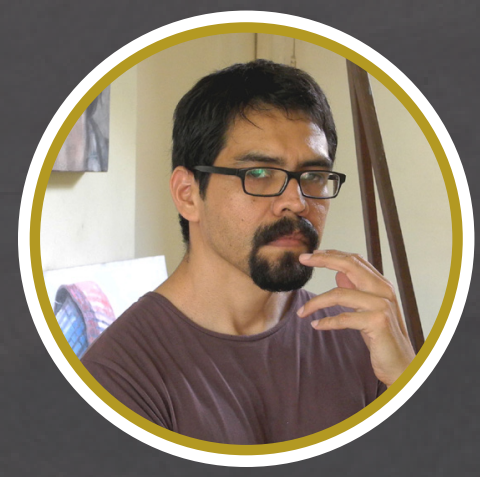

\section{Héctor Manuel Morales Orona}

Egresado de la Facultad de Artes Visuales de la Universidad Autónoma de Nuevo León. Inicia su profesión en el área de las artes gráficas, ilustrando en publicaciones de casas editoriales. Al mismo tiempo alterna esta actividad con la pintura mural. Después de este período inicial, su inquietud creativa se dirige al teatro, donde realiza estudios de arte dramático, cuyo aprendizaje originó nuevas reflexiones sobre el concepto de representación, y la experiencia del juego.

Más adelante, se dedica al estudio de las técnicas antiguas de la pintura haciéndolas su especialidad, y diversifica su profesión como pintor-dibujante y profesor de artes. Desde las técnicas antiguas y la importancia de los materiales, ha encontrado un campo nuevo de resignificaciones conceptuales, representando estas ideas sobre la materia, una fuerte línea de investigación que actualmente trabaja.

Cuenta con múltiples exposiciones colectivas e individuales. Ha participado en ediciones de la Reseña de la Plástica de Nuevo León y su obra se ha expuesto en México, Italia, Cuba y Canadá.

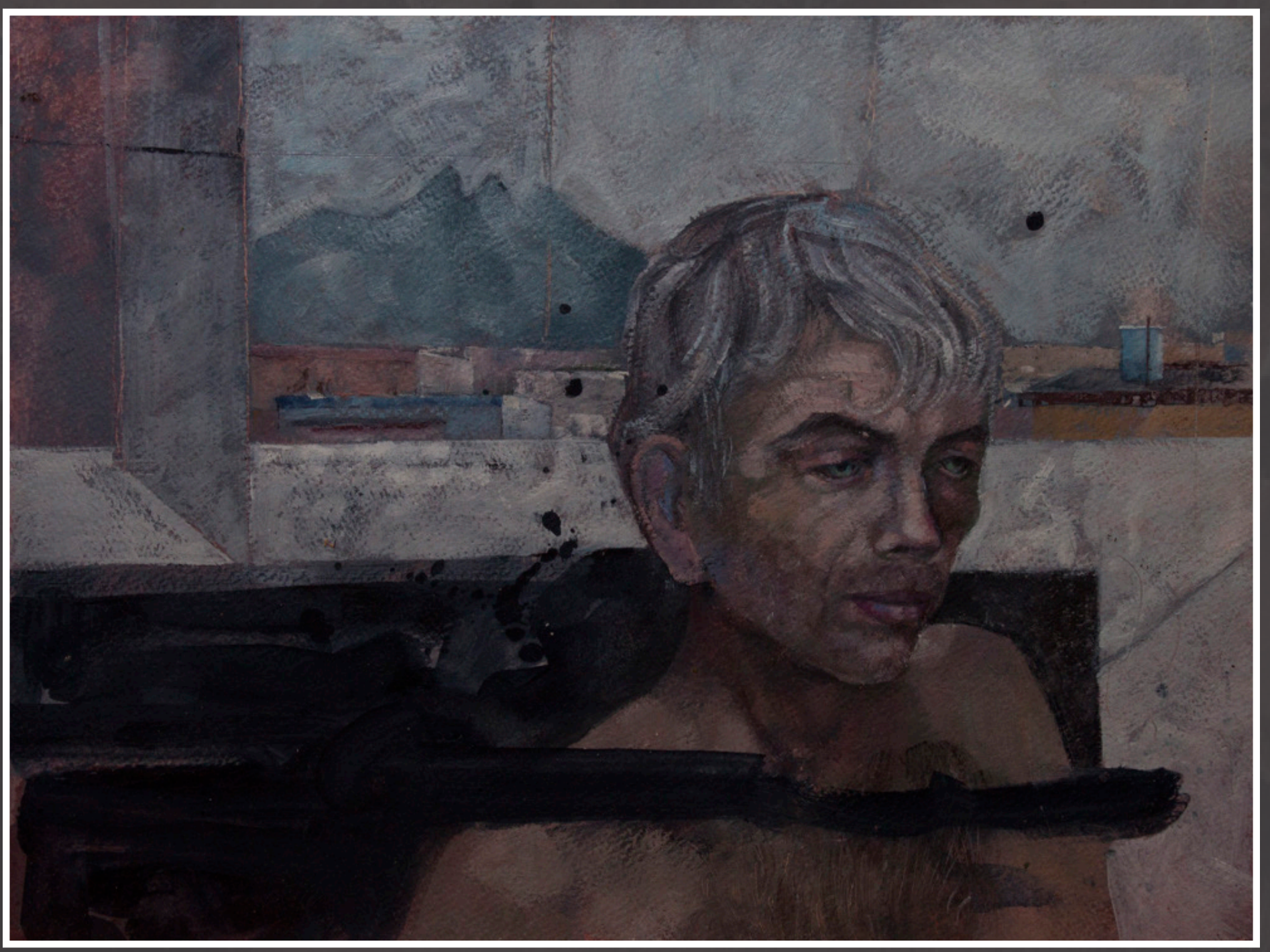

